\title{
A new approach to the analysis of multiple injuries using data from a national trauma registry
}

\author{
L Aharonson-Daniel, V Boyko, A Ziv, M Avitzour, K Peleg
}

Injury Prevention 2003;9:156-162

\begin{abstract}
Objective: To present a new systematic approach for summarizing multiple injury diagnosis data into patient injury profiles.

Design: International Classification of Diseases, ninth revision, clinical modification injury diagnosis codes were classified using a modification of the Barell body region by nature of injury diagnosis matrix, then grouped by body region, injury nature, or a combination of both. Profiles were built which describe patients' injury combinations based on matrix units, enabling the analysis of patients, and not only the study of injuries.

Setting: The Israeli national trauma registry was used to retrieve patient demographic data, injury details, and information on treatment and outcome.

Patients or subjects: All hospitalized patients injured in road traffic accidents and included in the trauma registry from January 1997 to December 2000 were included.

Main outcome measures: Patient profiles consisting of body regions, injury natures, their combination, and their clinical outcomes. Results: The study population comprised 17459 patients. Head and neck injuries were the most frequent in all subpopulations except for motorcyclists who sustained most injuries in the extremities. Fractures were the most common injury nature (60\%). Pedestrians and drivers had the highest proportion of multiple injuries in both profiles.

Forty eight percent of the patients had a single cell profile. The most frequent conditions as a sole condition were extremity fractures (14\%), internal injuries to the head $(11 \%)$, and injuries of other nature to the torso $(6 \%)$. Mortality, length of stay, and intensive care unit treatment varied dramatically between profiles and increased for multiple injury profiles. Inpatient death was an outcome for 3.3\% overall; however, in patients with an internal injury to the head and torso, inpatient death rate was nine times higher, at $31 \%$.

Conclusions: Profiles maintain information on body region and nature of injury. The use of injury profiles in describing the injured improves the understanding of casemix and can be useful for efficient staffing in multidisciplinary trauma teams and for various comparisons.
\end{abstract}

See end of article for authors' affiliations Correspondence to: Dr Limor

Aharonson-Daniel, Israel National Center for Trauma and Emergency Medicine Research, Gertner Institute for Epidemiology and Health Policy Research, Sheba Medical Center, Tel Hashomer, Israel 52621 limorad@gertner.health.gov.i

$\mathrm{T}$ he complexity associated with the treatment and outcome of multiple injuries brought about the development of various methods, from the injury severity score ${ }^{1}$ (ISS) in 1974 , the anatomic profile, ${ }^{2}$ the new ISS, ${ }^{3}$ and others ${ }^{45}$ to the workload scoring system ${ }^{6}$ in 2002 . However, the focus of these approaches was the contribution of multiple injuries to severity, to workload, or to cost, ${ }^{7}$ without portraying the injury sustained. A comprehensive description of the injury is valuable from clinical, epidemiological, and injury prevention perspectives.

Using multiple diagnoses combinations it is possible to identify all patients with a specific injury, providing a better description of hospital workloads, and present a more accurate pattern of injury in the individual. An injury profile that systematically looks at injury diagnosis combinations has not been reported to date. The Barell matrix provides a standard classification for the International Classification of Diseases, ninth revision (ICD-9-CM $)^{10}$ codes by body region and nature of injury. ${ }^{89}$ This classification enables the use of multiple diagnoses combinations to portray and analyze injuries in a population. Using this approach, data on road traffic casualties, extracted from the Israeli national trauma registry, are described with a focus on the methods for the analysis of multiple injuries.

\section{AIMS AND OBJECTIVES}

The aim is to produce a structured summary of multiple injury data, enabling comparisons between different times, different external causes, between hospitals, and ultimately between countries.

Specific objectives were:

- To apply a new approach for summarizing multiple injury diagnosis data into injury profiles.

- To examine procedures, duration of stay, and disposition for various injury profiles.

\section{METHODS}

\section{Population}

The study population consisted of all hospitalized patients injured in road traffic accidents included in the Israeli national trauma registry from January 1997 to December 2000. The registry comprises of all first admissions to eight hospitals (all level I and two level II trauma centers), emergency department deaths (excluding those who were dead on arrival), and transfers to other acute care hospitals. For this paper, information was retrieved from the registry and included patient diagnoses (up to 10 ICD-9-CM diagnoses per patient), age, sex, external cause of injury (E code), abbreviated injury scale, ${ }^{11}$ ISS, ${ }^{1}$ length of hospitalization, stay in the intensive care unit, and disposition. Patients injured in

Abbreviations: ICD-9-CM, International Classification of Diseases, ninth revision, clinical modification; ISS, injury severity score 


\begin{tabular}{|c|c|c|c|c|c|c|}
\hline \multirow{2}{*}{\multicolumn{2}{|c|}{$\begin{array}{l}\text { The } \\
\text { Barell } \\
\text { matrix }\end{array}$}} & $\mathbf{A}$ & B & C & D & $\mathbf{E}$ \\
\hline & & $\begin{array}{l}\text { FRACTURE } \\
800-829\end{array}$ & \begin{tabular}{|c|} 
INTERNAL \\
$850-854,860-869$ \\
$952,995.55$
\end{tabular} & \begin{tabular}{|l} 
OPEN WOUND \\
$870-884,890-894$ \\
\end{tabular} & $\begin{array}{l}\text { BURNS } \\
940-949\end{array}$ & $\begin{array}{c}\text { OTHER } \\
830-854,860-869,885-887,895-897 \\
900-904,910-929,950-957,959\end{array}$ \\
\hline \multicolumn{2}{|c|}{\begin{tabular}{|l|l|l} 
Barell row/column) \\
\end{tabular}} & (A) & (D) & (E) & (J) & $(\mathbf{B}, \mathbf{C}, \mathbf{F}, \mathbf{G}, \mathbf{H}, \mathbf{l}, \mathbf{K}, \mathbf{L})$ \\
\hline $\begin{array}{c}1 \\
\text { (39) } \\
\end{array}$ & 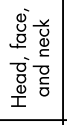 & $\begin{array}{l}800-804 \\
807.5-.6\end{array}$ & $850-854,995.55$ & $870-874$ & $\begin{array}{c}940-941 \\
947.0\end{array}$ & $\begin{array}{c}830,848.0-.2 \\
900,910,918,920,921 \\
925.1-.2,950-951 \\
953.0,954.0,957.0,959.01, .09 \\
\end{array}$ \\
\hline $\begin{array}{c}2 \\
(42) \\
\end{array}$ & 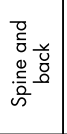 & $805-806$ & 952 & I & I & $\begin{array}{l}839.0-.5 \\
847.0-.4\end{array}$ \\
\hline $\begin{array}{c}3 \\
(43) \\
\end{array}$ & 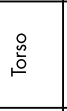 & $\begin{array}{l}807.0-.4 \\
808-809\end{array}$ & $\begin{array}{c}860-868 \\
1 \\
\end{array}$ & $\begin{array}{c}875,879.0-.7 \\
876-878\end{array}$ & 942 & $\begin{array}{c}839.6-.7,846,847.9,848.3-.5 \\
901,902.0-.5, .81-.82 \\
911,922,926,959.1 \\
953.1-.3, .5,954.1, .8-.9 \\
\end{array}$ \\
\hline (46) & 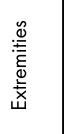 & $\begin{array}{l}810-818 \\
820-827\end{array}$ & / & $\begin{array}{l}880-884 \\
890-894\end{array}$ & $943-945$ & $\begin{array}{c}831-838,840-845,885-887,895-897 \\
903,904.0-8,912-917,923,924.0-.5 \\
927-928,953.4,955,959.2-.7\end{array}$ \\
\hline (49) & 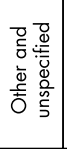 & $819,828-829$ & 869 & $879(.8-.9)$ & $\begin{array}{l}947.1-.2, .8-.9 \\
946,948,949\end{array}$ & $\begin{array}{c}839.8-.9,848.8-.9 \\
902.87, .89, .9,904.9 \\
919,924.8, .9,929,953.8,956 \\
953.9,957.1, .8, .9,959.8-.9\end{array}$ \\
\hline
\end{tabular}

Figure 1 A $5 \times 5$ injury diagnosis matrix, derived from the standard* classification by body region and nature of the injury. ${ }^{*}$ The full Barell matrix appears in Injury Prevention, June 2002 and can be found at http://www.cdc.gov/nchs/about/ otheract/ice/barellmatrix.htm.

a road traffic accident were defined as those with an external cause of injury code from E800.0 to E848.9, E929.0, and E 929.1. Any injury recorded in the database was included in the analysis. The method presented here applies to databases that include the option for recording more than one diagnostic injury code.

\section{Conceptual framework}

The framework for injury diagnoses analysis was based on a body region by nature of injury matrix. ${ }^{89}$ This, the Barell matrix, displays all injury ICD-9-CM codes (range from 800 to 995), each in a unique cell location in a two dimensional array. The nature of injury is presented in 13 columns, based on the sequence of codes detailed in the ICD-9-CM classification ${ }^{10}$ and the body region in 36 rows, with standard groupings into nine and five rows. The matrix enables standardized choices of injury diagnostic groups by injured body region (row), injury nature (column), or a combination of both (cell). Data analysis focuses on the general level first, studying the distribution of diagnoses and not by patient. Diagnostic group combinations were then built and their frequency examined. These combinations can be built on either dimension of the matrix. For the analysis presented below, the matrix was used at its most general level, which includes five body regions: head and neck, spine and back, torso, extremities, other, and unspecified. Nature of injury was also used in a modified format which includes five categories: fractures, internal injuries, open wounds, burns, and other. This modified version of the matrix is presented in fig 1 .

When building body region combination profiles, all natures were clustered into one column. For building injury nature profiles, body regions were minimized to one row. The final stage involved examining the combination of cells that provide the most specific level of detail on injury combinations. Cell combination profiles took into account both matrix dimensions. Matrix rows were noted by numeric characters 1 through 5, matrix columns by alpha numeric characters A to $\mathrm{E}$, and cells were represented by number-letter pairs defining patients "locations" in the matrix, similar to the way locations are noted on a chess board (Al to E5). Cell combinations used a string of such pairs to denote multiple injuries.

For analyzing multiple injuries using this method, we substitute the ICD-9-CM diagnostic code with the corresponding matrix cell so that our fundamental injury descriptor becomes a matrix cell. The terminology for "multiple" is then derived from the definition of the basic units in the analysis. Multiple injuries were defined as injuries that fell into more than one group with the group defined as the basic unit studied: body region, injury nature, or matrix cells.

For the ease of presentation and to avoid long lists of rare combinations, frequent combinations were selected as a standard injury descriptor while non-frequent combinations

Table 1 Population, injury and hospital service utilization characteristics by external cause of injury

\begin{tabular}{|c|c|c|c|c|c|c|c|}
\hline & \multirow[b]{2}{*}{ Total } & \multicolumn{6}{|c|}{ External cause of injury } \\
\hline & & Driver & Passenger & Motorcycle & Bicycle & Pedestrian & Other \\
\hline No (\%) population & $17459(100)$ & 4471 (25.6) & 3295 (18.9) & $1830(10.5)$ & $1904(10.9)$ & 4881 (28.0) & $1078(6.2)$ \\
\hline \multicolumn{8}{|l|}{ Age (years) } \\
\hline $0-14$ & 25.0 & 0.0 & 24.1 & 1.5 & 64.6 & 43.2 & 18.9 \\
\hline $15-29$ & 36.4 & 49.5 & 41.0 & 68.2 & 16.8 & 15.3 & 44.6 \\
\hline $30-44$ & 16.2 & 27.1 & 14.9 & 18.9 & 7.4 & 9.3 & 17.8 \\
\hline $45-59$ & 10.6 & 15.0 & 10.3 & 9.2 & 5.0 & 9.2 & 10.9 \\
\hline $60+$ & 11.8 & 8.4 & 9.7 & 2.2 & 6.2 & 23.0 & 7.8 \\
\hline Male (\%) & 69 & 76 & 50 & 89 & 84 & 62 & 69 \\
\hline Severity, ISS 16+ (\%) & 18 & 20 & 19 & 14 & 10 & 21 & 14 \\
\hline Operation (\%) & 31 & 29 & 26 & 49 & 23 & 33 & 31 \\
\hline Stay in ICU (\%) & 14 & 14 & 15 & 10 & 7 & 18 & 12 \\
\hline Median (IQR) LOS in days & $3(1-8)$ & $3(1-8)$ & $3(1-7)$ & $4(2-8)$ & $2(1-4)$ & $4(1-10)$ & $2(1-6)$ \\
\hline Inpatient death (\%) & 3.3 & 2.7 & 2.6 & 2.2 & 1.6 & 6.0 & 1.2 \\
\hline
\end{tabular}



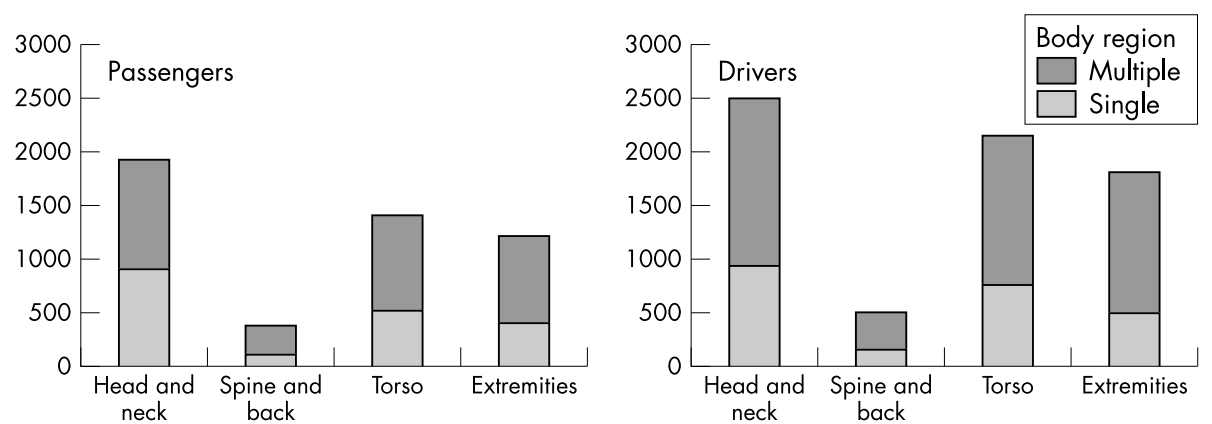

Figure 2 Distribution of body region injured by external cause of injury, single or multiple. Multiple injuries were defined as injuries that fell into more than one body region group; a patient with a multiple injury will appear in more than one bar.
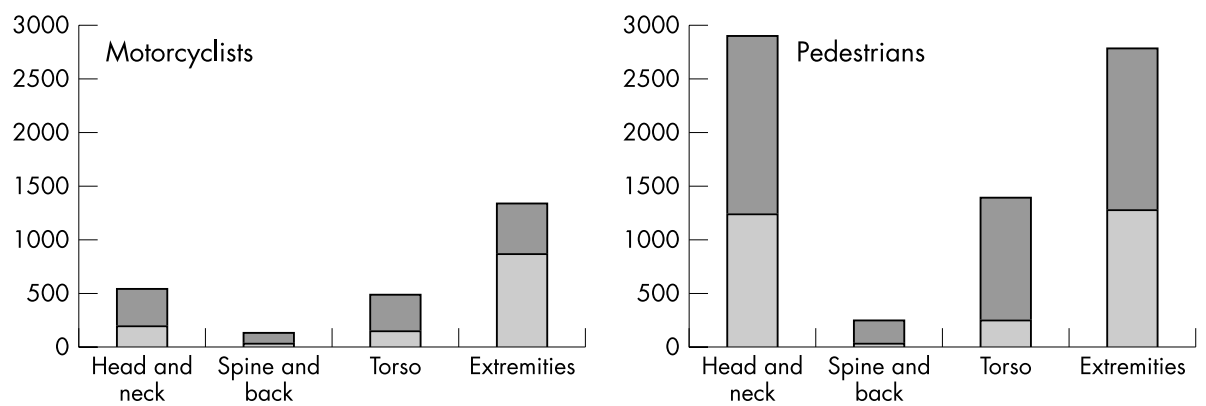

were combined in one category named "other multiple". Each combination group (called profile) was then examined for severity, treatments provided, service utilization, external cause of injury, and disposition.

\section{Data analysis}

Data analysis was conducted using SAS software. Patients' ICD-9-CM diagnostic codes were allocated to the appropriate matrix cells and retrieved for analysis by matrix categories: rows, columns, or cells. A program that collects all matrix cells and assigns them to the appropriate combination was written.

\section{RESULTS}

\section{Demographics and external cause of injury}

The study population comprised 17459 patients recorded in the trauma registry after a road traffic crash from January 1997 to December 2000 (table 1). Forty five percent of the casualties were sustained in four wheel motor vehicles: $26 \%$ as drivers and $19 \%$ as passengers. Pedestrians were the second largest group of external cause of injury (28\%). Additionally, there were $11 \%$ each involving motorcycle and bicycle riders. The category for "other" includes various injuries such as animal riders, agricultural vehicles, etc. There were more males in the injured population with the exception of the passenger group where both sexes were equal. The age of the population distributed differently in each injury circumstance group, resembling the anticipated proportion of users in each age group. For example, $66 \%$ of the pedestrians were younger than 14 or older than 60 while $68 \%$ of the motorcyclists were 15-29 years.

\section{Severity, treatment, and outcome by external cause of injury}

Pedestrians experienced the most severe or fatal injuries: $21 \%$ had an ISS of 16, intensive care unit treatment was necessary for $18 \%$, and $6 \%$ died in hospital. The inpatient death rate of

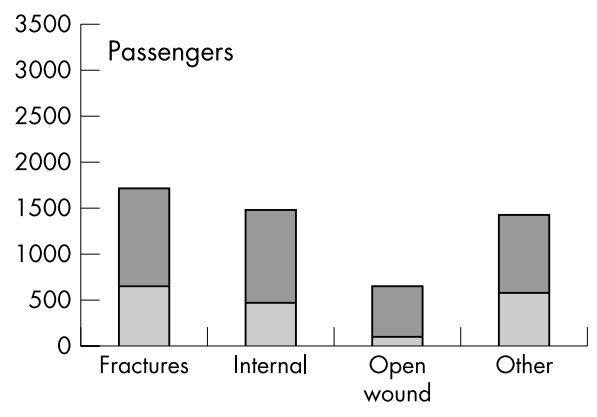

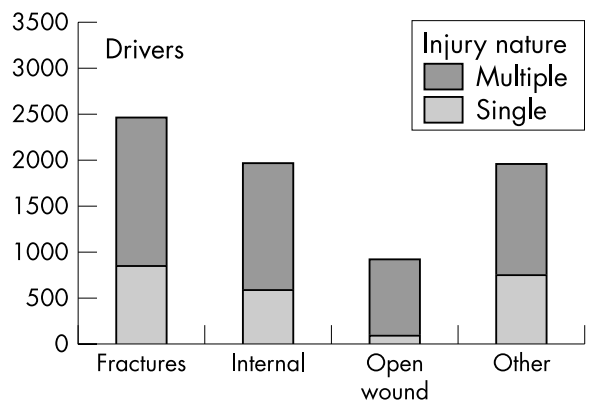

Figure 3 Distribution of injury nature by external cause of injury, single or multiple. Burns were not found to be a frequent nature of injury in road traffic accidents and were therefore excluded from this presentation. Multiple injuries were defined as injuries that fell into more than one body region group; a patient with a multiple injury will appear in more than one bar.
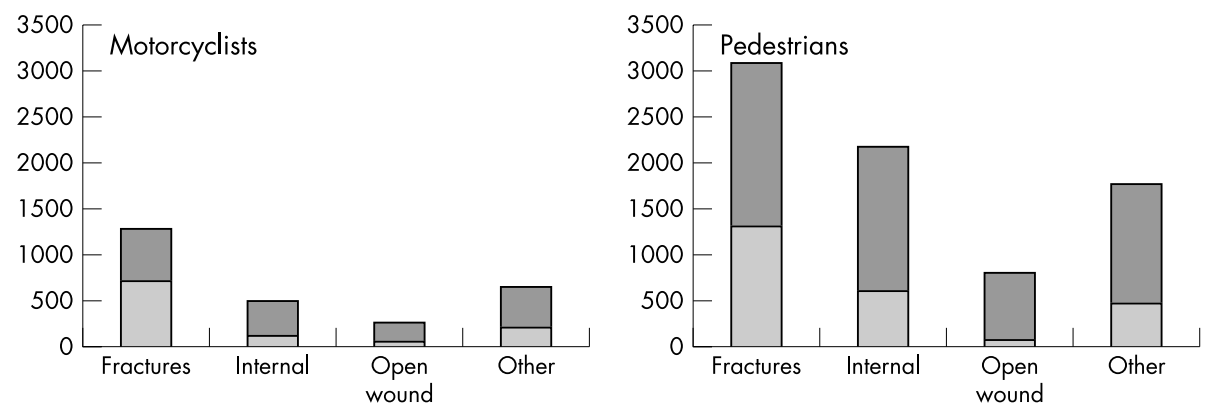


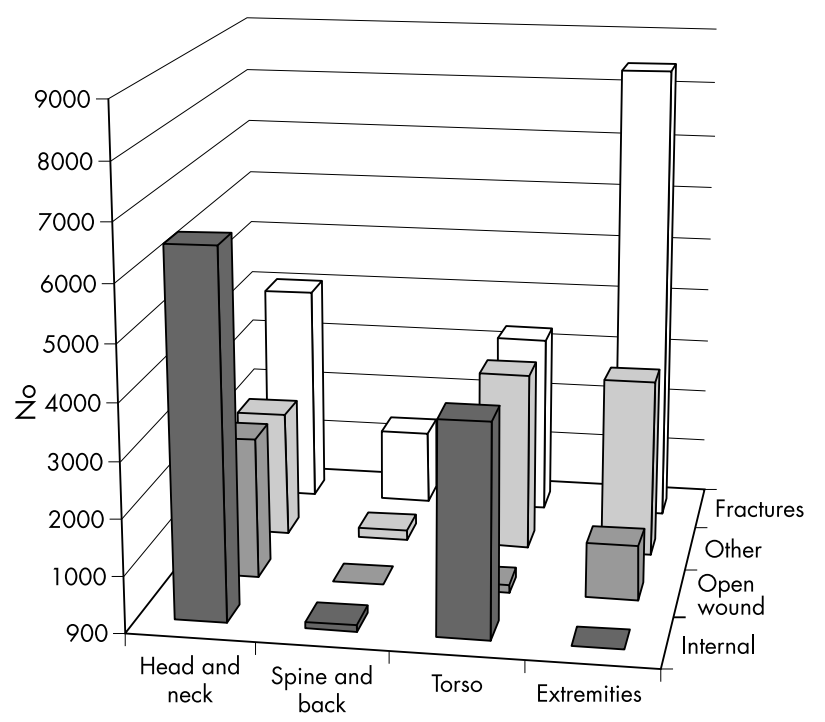

Figure 4 Distribution of body region by injury nature. Burns were not found to be a frequent nature of injury in road traffic accidents and were therefore excluded from this presentation. A patient with a multiple injury will appear in more than one bar.

pedestrians is double than that of any other injury circumstance. Motor vehicle drivers and passengers sustained severe injuries as well: $20 \%$ had an injury with an ISS of $16,14 \%$ had stayed in the intensive care unit, and $2.7 \%$ died in hospital.
The largest proportion of surgery or operative procedures was carried out on motorcyclists due to fractured extremities.

\section{Multiple diagnoses}

Forty eight percent had a diagnosis in one matrix cell, $61 \%$ had a diagnosis in one body region (row), and 55\% had one nature (column) of diagnosis.

\section{Stage 1: focus on diagnoses}

Figure 2 depicts the distribution of body region injured by external cause of injury. Head and neck injuries were the most frequent in all groups except for motorcyclists. Injuries to motorcyclists were mostly to the extremities. Pedestrians and drivers had the highest proportion of multiple injuries.

Figure 3 describes the distribution of injury nature and shows that fractures were the most frequent injury (60\%). Forty three percent of the fractures were as a single injury and more so in motorcyclists $(55 \%)$ than in car drivers and passengers $(35 \%)$. Internal injuries were present in $43 \%$, the majority $(70 \%)$ as part of a multiple injury.

Figure 4 displays the two dimensional distribution of injuries by body region and nature of injury. The most frequent injuries were internal injuries to the head and fractures of the extremities.

\section{Stage 2: injury profiles}

The frequency distribution of body region combinations and injury nature combinations (profiles) are presented in table 2. This distribution is detailed by external cause of injury (drivers, passengers, motorcyclists, bicyclists, pedestrians, and other) and by several characteristics of hospital service use

Table 2 Body region/nature of injury combinations by external cause of injury, intensive care unit ( ICU) stay, operations, length of stay (LOS), and outcome; values are percent unless stated otherwise

\begin{tabular}{|c|c|c|c|c|c|c|c|c|c|c|c|c|c|c|c|}
\hline \multirow{2}{*}{\multicolumn{5}{|c|}{ Group combinations }} & \multirow[b]{2}{*}{$\begin{array}{l}\text { All } \\
(n=17459)\end{array}$} & \multicolumn{6}{|c|}{ External cause of injury } & \multicolumn{4}{|c|}{$\begin{array}{l}\text { Utilization of hospital services and outcome } \\
(n=583)\end{array}$} \\
\hline & & & & & & $\begin{array}{l}\text { Driver } \\
(n=4471)\end{array}$ & $\begin{array}{l}\text { Passenger } \\
(n=3295)\end{array}$ & $\begin{array}{l}\text { Motorcycle } \\
(\mathrm{n}=1830)\end{array}$ & $\begin{array}{l}\text { Bicycle } \\
\text { ( } n=1904)\end{array}$ & $\begin{array}{l}\text { Pedestrian } \\
(n=4881)\end{array}$ & $\begin{array}{l}\text { Other } \\
(n=1078)\end{array}$ & ICU & $\begin{array}{l}\text { Median } \\
\text { (IQR) LOS } \\
\text { in days }\end{array}$ & Oper & $\begin{array}{l}\text { Inpatient } \\
\text { s death }\end{array}$ \\
\hline \multicolumn{16}{|c|}{ Body region } \\
\hline 1 & - & - & - & - & 24.9 & 21.3 & 27.6 & 10.2 & 40.1 & 25.4 & 27.2 & 10.2 & $2(1-4)$ & 11.7 & 2.2 \\
\hline - & 2 & & - & - & 2.4 & 3.8 & 3.5 & 1.9 & 1.3 & 0.7 & 3.7 & 5.0 & $3(2-6)$ & 12.7 & 0.7 \\
\hline- & - & 3 & - & - & 11.5 & 17.1 & 15.6 & 8.0 & 9.9 & 5.2 & 13.3 & 7.0 & $2(1-4)$ & 10.3 & 2.5 \\
\hline- & - & - & 4 & - & 21.5 & 11.2 & 11.9 & 47.2 & 24.6 & 26.1 & 24.1 & 2.4 & $4(2-9)$ & 57.8 & 0.2 \\
\hline 1 & - & 3 & - & - & 7.6 & 10.7 & 9.2 & 2.9 & 4.3 & 7.1 & 5.5 & 26.2 & $3(1-8)$ & 20.4 & 9.6 \\
\hline 1 & - & - & 4 & - & 11.1 & 9.7 & 9.3 & 8.7 & 11.1 & 14.9 & 9.00 & 14.5 & $4(2-9)$ & 37 & 1.9 \\
\hline - & - & 3 & 4 & - & 5.3 & 6.6 & 5.1 & 7.2 & 1.7 & 4.9 & 4.9 & 25.1 & $6(2-15)$ & 45.7 & 4.0 \\
\hline 1 & - & 3 & 4 & - & 6.4 & 8.5 & 6.5 & 4.4 & 2.3 & 7.4 & 4.3 & 41.9 & $8(3-17)$ & 47.6 & 11.9 \\
\hline 1 & 2 & 3 & 4 & 5 & 9.3 & 11.1 & 11.4 & 9.5 & 4.8 & 8.2 & 8.0 & 28.2 & $6(2-16)$ & 33.8 & 5.7 \\
\hline \multicolumn{16}{|c|}{ Injury nature } \\
\hline A & - & - & - & - & 24.8 & 18.7 & 19.5 & 38.7 & 25.6 & 27.1 & 31.1 & 7.6 & $4(2-9)$ & 48.7 & 1.3 \\
\hline - & B & - & - & - & 13.1 & 12.8 & 14.0 & 6.4 & 18.7 & 12.6 & 15.5 & 10.6 & $1(1-3)$ & 6.5 & 3.8 \\
\hline - & - & C & - & - & 2.5 & 2.0 & 2.7 & 3.1 & 5.1 & 1.7 & 2.5 & 1.1 & $3(1-4)$ & 36.6 & 0.2 \\
\hline - & - & - & - & $\mathrm{E}$ & 13.6 & 16.3 & 17.1 & 11.3 & 13.6 & 9.6 & 14.0 & 1.3 & $1(1-2)$ & 5.7 & 0.3 \\
\hline A & B & - & - & - & 9.8 & 9.7 & 9.9 & 8.8 & 6.1 & 12.0 & 8.6 & 43.8 & $7(3-16)$ & 42 & 11.8 \\
\hline A & B & C & - & - & 2.8 & 3.9 & 2.9 & 1.9 & 1.1 & 3.0 & 2.3 & 48.2 & $8.5(4-18)$ & 52.2 & 9.7 \\
\hline A & B & C & - & $E$ & 1.7 & 2.2 & 2.1 & 1.1 & 1.0 & 1.6 & 0.7 & 35.6 & $\begin{array}{l}7.5 \\
(3.5-15)\end{array}$ & 45.3 & 4.5 \\
\hline$A$ & B & - & - & $E$ & 4.5 & 4.9 & 4.7 & 4.7 & 2.4 & 5.2 & 3.3 & 42.7 & $8(3-17)$ & 46 & 10.7 \\
\hline$A$ & - & C & - & - & 3.9 & 5.0 & 3.7 & 3.0 & 3.0 & 3.9 & 2.8 & 13.3 & $6(3-11)$ & 56.1 & 0.9 \\
\hline A & - & C & - & $E$ & 1.8 & 2.1 & 1.9 & 1.7 & 1.1 & 1.8 & 1.3 & 16.3 & $7(4-13)$ & 56.9 & 1.0 \\
\hline A & - & - & - & $E$ & 8.4 & 8.6 & 7.5 & 11.4 & 5.6 & 8.8 & 8.0 & 8.3 & $4(2-10)$ & 42.1 & 2.0 \\
\hline- & B & C & - & - & 2.3 & 2.2 & 3.0 & 1.2 & 3.2 & 2.1 & 1.2 & 16.2 & $2(1-5)$ & 12.4 & 2.3 \\
\hline- & B & C & - & $E$ & 1.5 & 1.6 & 1.6 & 0.8 & 2.2 & 1.5 & 1.0 & 6.8 & $2(1-4)$ & 10.2 & 0.4 \\
\hline- & B & - & - & E & 6.6 & 6.8 & 6.5 & 3.3 & 9.2 & 6.8 & 5.1 & 7.4 & $1(1-3)$ & 6.2 & 2.2 \\
\hline- & - & C & - & $E$ & 1.4 & 1.4 & 1.7 & 1.5 & 1.3 & 1.3 & 1.4 & 3.2 & $2(1-5)$ & 21.9 & 0.4 \\
\hline A & B & C & D & $\mathrm{E}$ & 1.3 & 1.8 & 1.2 & 1.1 & 0.8 & 1.0 & 1.2 & 12.0 & $3(1-8)$ & 17.8 & 4.9 \\
\hline
\end{tabular}

$1=$ Head and neck, $2=$ spine and back, $3=$ torso, 4 =extremities, $5=$ other, 12345 includes combinations of 3 , 4, or 5 body regions with frequencies $<1 \%$ of total.

$A=$ Fractures, $B=$ internal, $C=$ open wound, $D=$ burns, $E=$ other (dislocations, sprains and strains, amputations, blood vessels, contusions, crush, nerves). $I Q R$, interquartile range. 
Table 3 Body region and nature of injury (cell) combinations by intensive care unit (ICU) stay, operations, length of stay (LOS), and outcome

\begin{tabular}{|c|c|c|c|c|c|}
\hline Cell combination & No (\%) total & ICU stay (\%) & $\begin{array}{l}\text { Median (IQR) LOS in } \\
\text { days }\end{array}$ & Operations (\%) & Inpatient death (\%) \\
\hline Total & $17459(100.0)$ & 14.2 & $3(1-8)$ & 31.2 & 3.3 \\
\hline Other & $4725(27.1)$ & 29.0 & $6(2-13)$ & 39.4 & 7.0 \\
\hline $4 \mathrm{~A}$ & 2485 (14.2) & 2.0 & $4(2-9)$ & 63.8 & 0.2 \\
\hline $1 B$ & 1927 (11.0) & 6.4 & $1(1-2)$ & 2.7 & 2.2 \\
\hline $3 E$ & $983(5.6)$ & 0.2 & $1(1-2)$ & 1.0 & 0.3 \\
\hline $1 \mathrm{~A}$ & $565(3.2)$ & 20.3 & $4(2-7)$ & 32.2 & 3.2 \\
\hline $4 \mathrm{E}$ & $488(2.8)$ & 2.3 & $2(1-5)$ & 21.9 & 0.2 \\
\hline $4 \mathrm{~A} .4 \mathrm{E}$ & $416(2.4)$ & 4.8 & $6(3-12)$ & 64.9 & 0.2 \\
\hline $3 A$ & $388(2.2)$ & 2.1 & $2(1-5)$ & 9.0 & 0.3 \\
\hline $\mathrm{IE}$ & $367(2.1)$ & 1.1 & $1(1-2)$ & 1.1 & 0.3 \\
\hline $2 \mathrm{~A}$ & 307 (1.8) & 4.9 & $4(2-6)$ & 14.0 & 0.3 \\
\hline $4 \mathrm{~A} .1 \mathrm{~B}$ & $271(1.6)$ & 17.3 & $4(2-8)$ & 34.3 & 1.9 \\
\hline 1B. $1 \mathrm{C}$ & 268 (1.5) & 8.2 & $2(1-3)$ & 6.7 & 0.4 \\
\hline $1 B .1 E$ & 267 (1.5) & 4.9 & $1(1-2)$ & 1.9 & 0.8 \\
\hline $1 \mathrm{~A} .1 \mathrm{~B}$ & $252(1.4)$ & 29.0 & $4(2-9)$ & 22.2 & 7.5 \\
\hline $1 C$ & $238(1.4)$ & 1.3 & $2(1-4)$ & 31.1 & 0.0 \\
\hline 1B.3E & $209(1.2)$ & 1.0 & $2(1-2)$ & 1.4 & 0.5 \\
\hline $3 B$ & $201(1.2)$ & 26.5 & 6 (2-9) & 30.4 & 7.5 \\
\hline $1 B .4 \mathrm{E}$ & $196(1.1)$ & 3.1 & $1(1-2)$ & 2.0 & 0.5 \\
\hline $3 \mathrm{~A} .4 \mathrm{~A}$ & 183 (1.0) & 18.6 & $7(3-16)$ & 46.5 & 2.7 \\
\hline $1 \mathrm{~A} .4 \mathrm{~A}$ & $151(0.9)$ & 32.5 & $7(3-16)$ & 56.3 & 2.7 \\
\hline $3 A .3 B$ & $147(0.8)$ & 33.8 & $8(3-14.5)$ & 31.3 & 9.5 \\
\hline $4 C$ & $145(0.8)$ & 0.0 & $3(2-5)$ & 44.1 & 0.7 \\
\hline $3 \mathrm{~A} .3 \mathrm{E}$ & $141(0.8)$ & 2.1 & $2(1-3)$ & 3.6 & 0.7 \\
\hline $4 \mathrm{~A} .4 \mathrm{C}$ & $133(0.8)$ & 3.0 & $6(4-13)$ & 74.2 & 0.0 \\
\hline $1 E .3 E$ & $131(0.8)$ & 0.8 & $2(1-2)$ & 0.0 & 0.0 \\
\hline $4 \mathrm{~A} .1 \mathrm{C}$ & $131(0.8)$ & 19.9 & $6(3-10)$ & 47.3 & 0.8 \\
\hline $1 \mathrm{~A} .1 \mathrm{C}$ & $128(0.7)$ & 4.7 & $5(3-8)$ & 60.2 & 0.0 \\
\hline $3 \mathrm{E} .4 \mathrm{E}$ & $103(0.6)$ & 0.0 & $2(1-3)$ & 2.9 & 0.0 \\
\hline $3 \mathrm{~A} \cdot 4 \mathrm{~A} \cdot 3 \mathrm{~B}$ & $101(0.6)$ & 53.5 & $12(4-23)$ & 44.6 & 8.9 \\
\hline $5 \mathrm{E}$ & $101(0.6)$ & 0.0 & $1(1-2)$ & 5.0 & 1.0 \\
\hline 1B. $3 B$ & $96(0.5)$ & 61.7 & $5(1-12)$ & 35.4 & 31.3 \\
\hline $4 \mathrm{~A} .1 \mathrm{E}$ & $96(0.5)$ & 4.2 & $3.5(2-8)$ & 40.6 & 0.0 \\
\hline 4A. $3 \mathrm{E}$ & $92(0.5)$ & 2.2 & $3(2-7)$ & 38.0 & 1.1 \\
\hline $1 \mathrm{E} .4 \mathrm{E}$ & $87(0.5)$ & 0.0 & $2(1-2)$ & 4.6 & 0.0 \\
\hline $1 \mathrm{~A} .1 \mathrm{E}$ & $79(0.5)$ & 16.9 & $4(2-6)$ & 16.5 & 1.3 \\
\hline $4 \mathrm{~A} .1 \mathrm{~B} .1 \mathrm{C}$ & $70(0.4)$ & 15.7 & $6(3-12)$ & 51.4 & 0.0 \\
\hline $1 \mathrm{~A} .3 \mathrm{~B}$ & $69(0.4)$ & 57.4 & $9(3-18)$ & 49.3 & 15.9 \\
\hline $1 B .5 E$ & $69(0.4)$ & 4.4 & $1(1-2)$ & 2.9 & 1.5 \\
\hline $1 \mathrm{~A} .4 \mathrm{~A} .1 \mathrm{~B}$ & $68(0.4)$ & 41.2 & $7(3-14)$ & 55.9 & 10.3 \\
\hline $4 A .3 B$ & $68(0.4)$ & 50.0 & $11(5-20)$ & 64.7 & 1.5 \\
\hline 1B. $1 \mathrm{E} .4 \mathrm{E}$ & $67(0.4)$ & 1.5 & $1(1-2)$ & 3.0 & 0.0 \\
\hline 3B. $3 \mathrm{E}$ & $64(0.4)$ & 18.8 & $6.5(3-11.5)$ & 39.1 & 10.9 \\
\hline 1B. 1E.3E & $59(0.3)$ & 0.0 & $1(1-2)$ & 0.0 & 0.0 \\
\hline $1 \mathrm{~A} .1 \mathrm{~B} .1 \mathrm{C}$ & $58(0.3)$ & 32.8 & $5(2-9)$ & 32.8 & 6.9 \\
\hline 1A. 1 B. $3 B$ & $57(0.3)$ & 70.2 & $8(2-16)$ & 56.1 & 33.3 \\
\hline $2 A .3 A$ & $55(0.3)$ & 7.3 & $10(5-18)$ & 14.6 & 0.0 \\
\hline $3 \mathrm{~A} .1 \mathrm{~B}$ & $54(0.3)$ & 18.5 & $3(1-11)$ & 11.1 & 5.6 \\
\hline 1B. 1C. $4 \mathrm{E}$ & $52(0.3)$ & 3.9 & $2(1-3)$ & 1.7 & 0.0 \\
\hline 4A. 1 B. 3 B & $51(0.3)$ & 68.6 & $9(2-23)$ & 58.8 & 29.4 \\
\hline
\end{tabular}

$1=$ Head and neck, $2=$ spine and back, $3=$ torso, $4=$ extremities, $5=$ other

$A=$ Fractures, $B=$ internal, $C=$ open wound, $D=$ burns, $E=$ other (dislocations, sprains and strains, amputations, blood vessels, contusions, crush, nerves). $I Q R$, interquartile range.

and outcome (intensive care unit treatment, length of stay, operations, or inpatient death).

The most frequent body region profile was a single injury to the head or neck $(25 \%)$ and to the extremities $(22 \%)$. These results vary by external cause; for example in motorcyclists, $47 \%$ suffered solitary injuries to the extremities and only $10 \%$ had head injuries. Most of the motorcyclists' other injuries involve extremities and another region. Pedestrians had head injuries (25\%), extremities (26\%), or both (15\%). Drivers injuries most commonly involved the head $(21 \%)$, the torso $(17 \%)$ or both $(11 \%)$.

Length of inpatient stay and death rates demonstrate clearly the contribution of the second and third injury in the multiply injured patient. While the inpatient duration of stay for a patient with a single injury ranged from a median of 2-4 days, the median for multiple injuries ranged from 3-8 days, with an interquartile range of up to 17 days for patients with triple injuries. The crude death rate was highest in patients who had triple injuries-that is, to head and neck, torso, and extremities, nearly $12 \%$. Deaths among patients with a single injury to the extremities was unexpected, and were therefore examined in more detail. These nine deaths involved patients aged 70-93, and may have been a result of some other comorbidity rather than the injury directly.

In terms of injury nature combinations, "fractures only" were the most frequent (25\%). Thirteen percent had only internal injuries and another $10 \%$ had a combination of fractures and internal injuries. The most severe outcomes were associated with multiple injury nature combinations. Patients with fractures and internal injuries suffered more severe outcomes as reflected by extended length of stay, stay in intensive care unit, and inpatient death rates.

Differences between various external causes of injury are apparent, with motorcyclists suffering the largest proportions 
of "fractures only" (39\%) and bicyclists suffering an excess of "internal only" injuries (19\%). Pedestrians had a relatively high proportion of multiple injuries, particularly a combination of fractures and internal injuries (12\%) (table 2).

Table 3 presents injury combinations (profiles) at the matrix cell level. The most frequent sole condition was extremity fractures $(14 \%)$. Eleven percent had internal injuries to the head and $6 \%$ had other injuries to the torso. The most common two cell combination was extremity fractures with "other" injuries to the extremities and extremity fractures with head injury $(2.4 \%$ and $1.6 \%$ respectively). None of the isolated extremity fractures sustained severe injuries compared to $98 \%$ of patients who had an extremity fracture accompanied by an internal head injury and an internal torso injury. Variations in injury severity and outcome are shown in table 3. Inpatient death was an outcome for $3.3 \%$, however, in patients with an internal injury to the head and torso, the inpatient death rate was $31 \%$.

\section{DISCUSSION}

Multiple injuries require timely and often multispecialty care and may be associated with greater severity and mortality than single injuries. The distribution of injuries sustained in road traffic accidents recorded in the Israeli national trauma registry included a large proportion of multiple injuries, emphasizing the need for a systematic approach for analyzing such data. Selecting a primary diagnosis or severity scoring ignoring the body region and nature of injury is not sufficient to provide a comprehensive picture of the injury. Injury profiles enable the identification of all cases with a specific injury and reflect both an accurate pattern of injury in the individual and a description of the hospital workload related to that injury.

Such a comprehensive view may have important implications for injury prevention.

Injury profiles are created based on ICD-9-CM ${ }^{10}$ codes as classified by the Barell injury diagnosis matrix ${ }^{89}$ enabling standardized comparisons of casemix and outcome between hospitals and countries. These profiles could also serve as a tool for planning the specialties needed in a multidisciplinary trauma team. The method presented is flexible and permits data analysis at a detailed or general level.

The use of a $5 \times 5$ derivation of the Barell matrix in this paper is meant for demonstrating the method for multiple injury profiles. The full detailed matrix ${ }^{8}{ }^{9}$ has been used by the authors to derive more submatrices for attaining the necessary resolution to suit specific study requirements. Selecting a few and rather broad categories as presented in this paper, enables presentation of the whole process and all combinations in a paper format, while using a larger number of cells in the matrix would have resulted in a larger number of combinations, making the presentation in this format impossible.

A review of the literature failed to find any descriptions of systematic approaches to the analysis of multiple injuries, beyond those which aim to predict severity or survival. ${ }^{5}{ }^{12}$ Most studies reviewed summarised injury diagnostic data using one diagnosis-either the first recorded or the primary diagnosis. ${ }^{13-15}$ Studies that took into account multiple injuries, either counted injuries regardless of how many patients had them, ${ }^{16}$ or selected the group definition a priori, and divided the population into these predefined groups. ${ }^{17}$ The fact that injury profiles enable counts of the number of injuries sustained and not just of the number of patients injured has important implications for health care management.

Drivers and passengers comprised the majority of victims of road traffic crashes. The most severe and fatal injuries involved pedestrians. Motorcyclists presented mostly with extremity fractures and a low proportion of head injuries. This low proportion of head injuries can be attributed to the fact that helmets are compulsory in Israel, and 98\% of those injured

\section{Key points}

- A new systematic approach for summarizing multiple injury diagnosis data into patient injury profiles.

- The method creates patient profiles that maintain information on body region and nature of injury and then monitors patient clinical outcomes for various profiles.

- Mortality, duration of hospitalization, and intensive care unit treatment varied dramatically between profiles and increased for multiple injury profiles.

- The use of injury profiles in describing the injured improves the understanding of casemix and can be useful for efficient staffing in multidisciplinary trauma teams and for various comparisons.

reported having used a helmet at the time. This finding is consistent with reports that more severe and fatal injuries occur in unhelmeted motorcyclists. ${ }^{18}$ The high proportion of male drivers in car and motorcycle crashes corresponds well with the proportion of males in the population with a driving license. Pedestrians and drivers had the highest proportions of multiple injuries.

An examination of the injury profile found that extremity fractures were the most frequent sole condition (14\%) followed by internal injuries to the head $(11 \%)$. The most common two cell combinations included the grouping of these two cells. Inpatient death rates demonstrated the effect of second and further injuries in the multiply injured patients on survival. Although ISS could reflect the true severity even in one diagnosis methods, the actual cause would be attributed to whatever injury was coded as primary rather than the more complex picture. For example, inpatient death rate in patients with an internal injury to the head alone was $2.2 \%$, to the torso alone $7.5 \%$, while a combined injury resulted in a $31 \%$ inpatient death rate. Using a one diagnosis summary would attribute the death to one of the two diagnoses. While this finding, that the combination of head and torso, rather than each of them by itself, is the risk factor, may not surprise clinicians, it validates the advantages of multiple injury profiles.

The flexibility of the method is based on the fact that the choice of matrix cells used to obtain the components of the profiles is subjective. It is the standard classification that leads to a universal definition of a multiple injury. Nevertheless, there are still some issues for consideration. If a patient sustained one injury to one body region and another in another region, it would be a multiple injury. However, if for example, a person has been injured in the arm and leg, accounting for two diagnoses in the same cell, the decision needs to be made if that is a single or multiple injury. If blisters or contusions were part of the injury, or the additional injuries are such that would not justify hospitalization, we can debate whether the patient should be considered one with a multiple injury.

In this paper two diagnoses in the same categorical group were not considered multiple whereas injuries to two diagnostic groupings were considered multiple. Future enhancements may attempt to standardize the definition of multiple injuries.

\section{ACKNOWLEDGEMENTS}

The authors would like to thank the hospitals taking part in the Israeli National Trauma Registry and express gratitude to the heads of trauma units, the trauma coordinators, and the registrars for their contribution to recording the data. Special recognition is due to members of the International Collaborative Effort (ICE) on Injury Statistics who were among the first audiences to hear and comment on this approach and have a significant role in its development. Finally, we would like to recognize the contribution of the late Vita Barell who had set the path, took the first steps, and left us to complete her course. 


\section{Authors' affiliations}

L Aharonson-Daniel, V Boyko, A Ziv, M Avitzour, K Peleg, Israe National Center for Trauma and Emergency Medicine Research, Gertner Institute for Epidemiology and Health Policy Research, Tel Hashomer, Israel

\section{REFERENCES}

1 Baker SP, O'Neill B, Haddon W, et al. The injury severity score: a method for describing patients with multiple injuries and evaluating emergency care. J Trauma 1974;14:187-96.

2 Copes WS, Champion HR, Sacco WJ. Progress in characterising anatomic injury. J Trauma 1990;30:1200-7.

3 Rutledge R, Osler T. The ICD-9 based illness severity score: a new model that outperforms both DRG and APR-DRG as predictors of survival and resource utilization. J Trauma 1998:45:792-9.

4 Osler T, Baker SP, Long W. A modification of the injury severity score that both improves accuracy and simplifies scoring. J Trauma 1997;43:922-5.

5 Sacco WJ, Mackenzie EJ, Champion HR, et al. Comparison of alternative methods for assessing injury severity based on anatomic descriptors. J Trauma 1999:47:441-6.

6 Huang MS, Yang YF, Lee CH. Evaluation of staff workload during resuscitation of trauma patients. J Trauma 2002;52:492-7.

7 Mackenzie EJ, Steinwachs DM, Ramzy Al, et al. Trauma case mix and hospital payment: the potential for refining DRGs. Health Services Research 1991:26:4-25.
8 Barell V, Aharonson-Daniel L, Fingerhut LA, et al. An introduction to the Barell body region by nature of injury diagnosis matrix. Inj Prev 2002:8:91-6.

9 CDC. http://www.cdc.gov/nchs/about/otheract/ice/barellmatrix.htm

10 Practice Management Information Corporation. International classification of diseases, 9th revision, clinical modification, 5th edition (ICD-9CM). Los Angeles: PMIC, 1998

11 Association for the Advancement of Automotive Medicine. Committee on Injury Scaling. The abbreviated injury scale-1990 revision (AIS-90). Des Plaines, IL: AAAM, 1990.

12 Meredith JW, Evans G, Kilgo PD, et al. A comparison of the abilities of nine scoring algorithms in predicting mortality. J Trauma 2002;53:621-9.

13 CDC, National Center for Health Statistics. Design and operation of the National Hospital Discharge Survey: 1988 redesign. Vital and Health Statistics Series 1, Number 39 (http://www.cdc.gov/nchs/about/ major/hdasd/nhdsdes.htm).

14 Langley JD, Phillips D, Marshall W. Inpatient costs of injury due to motor vehicle traffic crashes in New Zealand. Accid Anal Prev 1993:25:585-92.

15 Miller TR, Pindus NM, Douglass JB. Medically related motor vehicle injury costs by body region and severity. J Trauma 1993;34:270-5.

16 Regel G, Lobenhoffer P, Grotz M, et al. Treatment results of patients with multiple trauma: an analysis of 3406 cases treated between 1972 and 1991 at a German level 1 trauma center. J Trauma 1995:38:70-7.

17 Nathens AB, Jurkovich GJ, Maier RV, et al. Relationship between trauma center volume and outcomes. JAMA 2001;285:1164-71.

18 Rowland J, Rivara F, Salzberg P, et al. Motorcycle helmet use and injury outcome and hospitalization costs from crashes in washington state. Am J Public Health 1996:86:41-5.

Damaging documents expose industry evasion over fire safe cigarettes

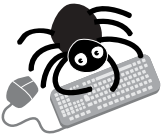

Please visit the Injury Prevention website [www. injuryprevention com] for link to this full article.
U to 1000 deaths a year from cigarette fires in the Unites States might have been prevented, but for the tobacco industry's covert opposition to legislation on safe cigarettes over the past 25 years, research on internal company documents has disclosed.

The documents made public under the 1998 Master Settlement Agreement should help federal law makers. They provide reliable evidence of the industry's tactics, from misleading the public about the feasibility of producing a fire safe cigarette to using political means to stave off legislation while masking that fact.

Companies' research into developing fire safe cigarettes stretches back to the late 1970s-though patents have existed since the 1930s and earlier-and shows that this is possible. Publicly, however, the industry has mounted counterarguments based variously on fear of being held liable for former (non-safe) brands, on consumers not accepting altered cigarettes, toxicity of low burn additives, and inadequacy of meaningful testing of ignition tendency. It has wooed fire service organisations at all levels - the main source of data on fire deaths - with large grants and has diverted attention away from cigarettes to overall fire safety measures by funding general fire safety programmes.

Philip Morris is the only company to have marketed a fire safe cigarette; that other companies have not demands federal legislation to force responsibility on an industry whose products are a leading cause of fire deaths in the US and an important cause globally.

About 200 company documents were used in the research.

A Tobacco Control 2002;11:346-353 